\title{
Oral Tongue Cancer: Literature Review and Current Management
}

\author{
Rodrigo Arrangoiz*, Fernando Cordera, David Caba, Eduardo Moreno, Enrique Luque de León and Manuel Muñoz \\ Sociedad Quirúrgica S.C., American British Cowdray Medical Center, Mexico
}

\begin{abstract}
In 2018, it is estimated that about 51, 540 new cases of oral cavity and pharyngeal cancer will develop, which represent approximately $3-5 \%$ of all cancers in the United States. During the same time period it is estimated that there will be approximately 10, 030 deaths. Incidence rates are more than twice as high in men as in women (Male cases-37,160, Female cases-14,380). From 2006 to 2010 incidence rates remained stable in men and have decreased by 0.9\% per year in women. Oral tongue cancer requires a multidisciplinary approach to treat it that includes a surgical oncologist, a medical oncologist, a radiation oncologist, speech therapists and physical rehabilitation as well as emotional support through the help of psychologists or social workers. In this review paper we will discuss current management of these complex tumor.
\end{abstract}

\section{Introduction}

In 2018 , it is estimated that about 51,540 new cases of oral cavity and pharyngeal cancer will develop, which represent approximately $3-5 \%$ of all cancers in the United States [1,2]. During the same time period it is estimated that there will be approximately 10, 030 deaths $[1,2]$. Incidence rates are more than twice as high in men as in women (Male cases-37,160, Female cases-14,380) [1]. From 2006 to 2010 incidence rates remained stable in men and have decreased by $0.9 \%$ per year in women [1]. From 2005 to 2014, incidence rates decreased by more than $2 \%$ per year among blacks, but increased by about $1 \%$ per year among whites, largely driven by rising rates for a subset of cancers associated with human papillomavirus (HPV) infection that arise in the oropharynx.

Death rates have been decreasing over the past three decades; from 2006 to 2010 , rates decreased by $1.2 \%$ per year in men and by $2.1 \%$ per year in women [1]. In 2018, it is estimated that 17,110 new cases of oral tongue cancer will occur, of this 12,490 will occur in men and 4620 will develop in women (one third of the cases will develop in women). The estimated death rate from oral tongue cancer in 2018 is 2,510 deaths (1750 in males and 760 in females) (Table 1) [1]. Most head and neck cancers present with metastatic disease at the time of diagnosis, with regional nodal involvement and distant metastatic disease in $43 \%$ and $10 \%$ of the cases, respectively [3].

Head and neck cancer patients often develop second primary tumors, this is because they share common risk factors [4]. These second primary tumors develop at an annual rate of 3-7\% and $50-75 \%$ of these new cancers are located in upper aero digestive tract or lungs [3].

\section{Surgical anatomy of the oral cavity}

- Boundaries of the oral cavity:

- Superior border-from the vermillion border to the junction of the hard and soft palates.

- Inferior border-from the vermillion border to the circumvallate papillae of the oral tongue.
- The lateral border-is the mucosa of the mouth up to the anterior tonsillar pillars.

The oral cavity includes the lips, buccal mucosa, upper and lower alveolar ridges, gingiva, retromolar trigone, floor of mouth, hard palate and the anterior two thirds of the tongue ("oral tongue"). The main lymphatic drainage is to level IA (submental triangle), IB (submandibular triangle) and II (upper deep jugular nodes) [5].

\section{Tongue anatomy}

The tongue which is located in the oral cavity and oropharynx is a mass of muscle that is almost completely covered by a thick mucous membrane. The primary function of the tongue is taste sensation, but it also assists with mastication, deglutition, articulation, and oral cleansing [6]. The complex innervation of this multifunctional organ is provided by five cranial nerves [7].

The embryologic origins of the tongue first appear at 4 weeks' gestation $[7,8]$. The first branchial arch is responsible for the development of the tongue derivatives. It gives rise to two lateral lingual swellings and one median swelling (known as the tuberculum impar) $[7,8]$. The two lateral lingual swellings grow over the tuberculum impar and merge, forming the anterior two thirds of the tongue [8]. Portions of the second, third, and fourth branchial arches give rise to the base of the tongue [9]. The intrinsic musculature of the tongue derives from occipital somites which give rise to myoblasts [8].

Macroscopically from anterior to posterior, the tongue has three surfaces: tip, body, and the base. The tip of the tongue is the highly

${ }^{*}$ Correspondence to: Rodrigo Arrangoiz MS, MD, FACS, Sociedad Quirúrgica S.C. at the American British Cowdray Medical Center, Av. Carlos Graef Fernandez \# 154-515, Colonia Tlaxala, Delegación, Cuajimalpa, Mexico, Tel: 1664 7200; E-mail: rodrigo.arrangoiz@gmail.com

Key words: oral cancer, oral tongue cancer, squamous cell carcinoma, diagnosis and treatment of oral tongue cancer

Received: April 22, 2018; Accepted: May 10, 2018; Published: May 14, 2018 
mobile, pointed, anterior portion of the tongue. Behind to the tip lies the body of the tongue, which has a dorsal (superior) and a ventral (inferior) surfaces. The median sulcus of the tongue separates the body into left and right halves. The terminal sulcus is a V-shaped furrow that separates the body of the tongue from the base of the tongue. At the tip of this sulcus is the foramen cecum, a remnant of the proximal thyroglossal duct. The base of tongue contains the lingual tonsils, the inferior most portion of Waldeyer's ring [7-9].

The body of the tongue derives its characteristic surface appearance from the presence of lingual papillae, which are projections of lamina propria covered with epithelium [6]. Four different types of lingual papillae exist: circumvallate (vallate), foliate, filiform, and fungiform [6]. The circumvallate papillae are flat, prominent papillae that are surrounded by troughs. There are approximately eight to 12 circumvallate papillae, located directly anterior to the terminal sulcus. The ducts of the lingual glands of von Ebner secrete lingual lipase into the surrounding troughs to begin the process of lipolysis [10]. On the lateral surface of the tongue foliate papillae are identified, they are small folds of mucosa. The filiform papillae are thin and long and they are the most abundant papillae in the tongue. They are located along the entire dorsum of the tongue, but they are not involved in taste sensation [6]. The mushroom shaped papillae and called the fungiform papillae. They are scattered most densely along the tip and lateral surfaces of the tongue. The human tongue has roughly 200 to 300 fungiform papillae.

Each circumvallate, foliate, and fungiform papilla contains taste buds $(250,1000$, and 1600 taste buds, respectively) [6], innervated by multiple nerve fibers. All taste buds can perceive the five different taste qualities: salt, sweet, bitter, acid, and umami. The taste bud consists of a taste receptor, basal cell, and edge cell. When a taste molecule binds to a taste receptor, the receptor cell depolarizes, causing an influx of $\mathrm{Ca}++$, which results in the release of an unidentified neurotransmitter [6]. Following the depolarization, the afferent neural pathway depends on the location of the taste bud that was stimulated. In the anterior two thirds of the tongue, the chorda tympani branch of the facial nerve (cranial nerve VII) is stimulated [6,11]. The lingual-tonsillar branch of the glossopharyngeal nerve (cranial nerve IX) relays taste information from the posterior third of the tongue $[6,11]$.

The tongue has four intrinsic and four extrinsic muscles [7,9,11]. The muscles on each side of the tongue are separated by a fibrous lingual septum. The extrinsic muscles are so named because they originate outside the tongue and insert within it and the intrinsic muscles are within the substance of the organ and do not insert on bone. Though the muscles do not act in isolation, intrinsic muscles generally alter the shape of the tongue, whereas extrinsic muscles alter its position [7]. The extrinsic muscles of the tongue are the genioglossus, hyoglossus, styloglossus, and palatoglossus [7]. The hypoglossal nerve provides the motor innervation to all muscles of the tongue except the palatoglossus, which is supplied by the pharyngeal plexus $[7,11]$.

The arterial supply to the tongue and floor of the mouth is derived from the dorsal lingual, sublingual, and deep lingual branches of the lingual artery [11]. The venous drainage of the tongue is into the lingual veins, which drain into the facial and retromandibular veins, which join to form the common facial vein.

The oral cavity is continuously, been exposed to inhaled and consumed carcinogens, and thus it is the most common site for the origin of malignant epithelial neoplasms in the head and neck region. The most common location for a malignant tumor of the oral cavity is the anterior two thirds of the tongue. Known carcinogens in the oral cavity include those present in tobacco, alcohol, and betel nuts. The relationship of human papilloma virus (HPV) with oral cancer is not as well established as in oropharyngeal cancers. Primary tumors of the oral cavity may arise from the surface epithelium, minor salivary glands, submucosal soft tissue, and tumors of dento-alveolar origin [11]. More than $90 \%$ of cancers in the oral cavity are squamous cell in origin and we will be focusing our review on these neoplasms.

\section{Epidemiology}

Malignant neoplasm of the tongue are by far more common in men than in women (66-95\% of cases), this is similar to the rest of the oral cavity [1]. The incidence by gender varies depending on the anatomic location and has been changing due to the increase in the number of women who smoke. The male to female ratio is currently $3: 1$ [1]. The incidence of oral cavity and tongue cancer increases with age, especially after age 50 . Most patients are between 50 and 70 years but can also occur in younger patients [3].

There are large differences in the incidence of oral cavity cancer among different geographical regions. The highest incidence of this disease is found in Asia and is believed to reflect the prevalence of certain risk factors, such as chewing betel nut $[12,13]$ and the use of smokeless tobacco (snuff) [14]. In the United States, in urban areas the high incidence among men is thought to reflect exposure to snuff and alcohol. Among women in rural areas in the United States the increase risk of oral cavity cancer is associated with the use of smokeless tobacco (snuff) [1].

\section{Etiology and risk factors}

One of the most important risk factors for the development of squamous cell carcinoma (SCC) of the tongue is tobacco. Smoking cigarettes, cigars, or pipes; chewing tobacco; and using snuff are the single largest risk factors for all head and neck cancer including the tongue. Eighty-five percent ( $85 \%$ ) of head and neck cancers are linked to tobacco use $[15,16]$. Secondhand smoke may also increase a person's risk of developing a head and neck cancer [17].

Based on epidemiologic studies, cigar smoking is an important risk factors for oral cavity tumors and the only difference between cigarette smoking and cigar smoking is that it instigates a change in the usual anatomic location for these tumors $[1,18]$. The use of smokeless tobacco is also associated with an increased incidence of cancer of the oral cavity $[1,2]$. Chewing snuff is the leading cause of SCC of the oral cavity and oropharynx in India, part of Southeast Asia, China, and Taiwan, especially when consumed with betel containing areca nut [19].

Alcohol by itself is a risk factor for the development of tongue and oral cavity cancer, although it is less potent carcinogen than tobacco $[20,21]$. People who use tobacco and alcohol, these risk factors appear to be synergistic and result in a multiplicative increase in risk, 30 to 36 times higher for people who smoke and drink heavily [22].

Edentulous patients and poor oral hygiene can be risk factors for cancer of the oral cavity $[23,24]$. The use of mouthwashes that have high alcohol content could be a risk factor for tongue and oral cavity SCC (unproven) [24,25]. The consumption of the tea beverage, mate (consumed by South Americans), has been associated with an increased risk of cancer of the oral cavity [26] .

Epidemiologic studies suggest that the intake of vitamin $\mathrm{A}$, $\beta$-carotene, and $\alpha$-tocopherol may reduce the risk of developing oral cavity cancers [27-32]. Certain syndromes caused by inherited defects 
(mutations) in certain genes have a very high risk of developing cancer of the oral cavity and tongue. Fanconi anemia is a disease that can be caused by inherited defects in several genes that contribute to DNA repair. People with this syndrome often have hematologic problems an early age, which can lead to leukemia or aplastic anemia. They also have a risk of developing cancer of the oral cavity, especially tongue cancer $[33,34]$. Dyskeratosis congenita is a genetic syndrome that can cause aplastic anemia, skin rashes, and nail abnormalities of the hands and feet; they also increase the risk of developing oral cavity cancer $[35,36]$.

\section{Mechanisms of carcinogenesis}

The development of tongue and oral cavity SCC is a multistep progression that involves changes related to specific genes, epigenetic events, and signal transduction within the cell [37]. Tobacco smoke contains agents that may act as mutagens. Also, tobacco smoke extract has been shown to activate the epidermal growth factor receptor (EGFR) in vitro and EGFR activation has been shown, in turn, to increase the production of prostaglandins, including PGE2 which may act in a positive feedback fashion by increasing EGFR signal transduction. Cyclin-D1 is frequently overexpressed in head and neck cancer and increased cyclin-D1 activity is a downstream event triggered by EGFR activation [38].

An important epigenetic event in the progression to cancer is the silencing of gene promoter regions through hypermethylation [39], which has been shown to affect the tumor suppressors p16, DAPkinase, and E-cadherin. Also, the gene for retinoic acid receptor-beta (RAR-beta) is silenced by methylation of its promoter [40].

Genetic alterations that are present early in the course of carcinogenesis are mutations or deletions of chromosome $3 p$ and $9 p$. Telomerase activation also occurs early in carcinogenesis. Mutations or deletions at chromosome $17 \mathrm{p}$ (involving the p53 tumor suppressor gene), and chromosome $13 \mathrm{q}$ and chromosome $18 \mathrm{q}$ generally are seen later in the process. Patients whose tumors contain HPV mRNA have a significantly lower rate of deletions of chromosomes $3 p, 9 p$, and $17 p$, suggesting an alternate molecular mechanism in these patients. The viral proteins E6 and E7 have been shown to cause deregulation of the cell cycle by inactivating p53 and retinoblastoma protein, which may be the mechanism of HPV-mediated carcinogenesis [41].

In addition to deletions or mutations of individual genes, evidence exists demonstrating that numeric chromosomal imbalances, known as aneuploidy, may be a cause rather than a consequence of malignant transformation [42]. Aneuploidy may occur as a result of mutations in genes controlling chromosome segregation during mitosis and centrosome abnormalities.

\section{Diagnosis}

The need for a rapid diagnosis and referral of patients to a skilled physician with expertise in the management of tumors of the head and neck is very important because early diagnosis can lead to a reduction in mortality [3]. The risk factors mention on the etiology section of this paper, including history of tobacco and alcohol use should be interrogated. Any adult patient with symptoms attributable to the upper aero digestive tract lasting more than two weeks or an asymptomatic cervical (neck) tumor should undergo a full examination with a high index of suspicion for malignancy [3].

The physical examination is the best way to detect lesions of the upper aero digestive tract. Often the initial assessment also indicates the severity and chronicity of the disease. Due to the frequent occurrence of synchronous primary tumors in patients with head and neck cancers (approximately 5\%), a careful evaluation of the entire upper aero digestive tract is required at the time of diagnosis [43].

Tongue cancers usually cause symptoms related to the upper aero digestive tract, including changes in swallowing, speech, hearing and breathing. During the interrogation the physician must give emphasis to the following symptoms: tongue pain, non-healing ulcer on the tongue, and changes in the ability to form words. A complete physical examination should be performed on every patient with specific emphasis on the head and neck exam (inspection, palpation, otoscopic exam, indirect laryngoscopy, and when indicated nasopharyngolaryngoscopy) and a neurological exam with emphasis on cranial nerves $\mathrm{V}$, through XII. The most common presenting complaint of patients with tongue tumors is a sore or lump. Cancer of the tongue mucosa may present as an indurated ulcer with raised edges (Figure 1) or as an exophytic growth. Bleeding from the surface of the lesion is a characteristic of malignancy and immediately raises suspicion for a neoplastic process. Approximately one third of the patients come in to the office with a neck lump [44].

Biopsy of the tongue lesion can often be performed in the office or as an outpatient surgery depending on the anatomic site and patient preference. One can perform the biopsy in the office setting using a punch biopsy or using biopsy forceps (Figure 2). The biopsy should be obtained from the edge of the lesion, away from areas of obvious necrosis or excess keratinization.

Fine needle aspiration (FNA) is a useful diagnostic modality [4547] for differentiating benign from malignant lymph nodes in the neck. A fine gauge needle (\#23 gauge) makes multiple passes over the lesion while continues suction is applied. Suction must be released before removing the needle of the lesion. This procedure has a false negative rate of 7\% [47]. Cytology is particularly useful to distinguish metastatic SCC from other malignant histology's. However, a negative result should not be interpreted as " absence of disease" when the clinical scenario is highly suspicions for malignancy. A core needle biopsy should not be performed in a lump in the neck, with the exception of an already diagnosed lymphoma. Martin Hayes in a communication to the medical profession in general stated "not only to the needlessness but also to the possible harmfulness of excisional lymph node biopsy as the first or even as an early step in the diagnosis of cancer" [48]. Open biopsies should be done only when the diagnosis has not been made after extensive clinical evaluation and after at least two non-diagnostic FNA's. The surgeon performing the open biopsy should be prepared to perform a definitive surgical treatment at that moment in time, which may involve a formal neck dissection if the diagnosis turns out to be a SCC.

Computed tomography (CT) is probably the most informative test in the evaluation of tumors of the oral cavity and tongue [49]. It can help define the extent of disease and the presence and extent of lymph node involvement. CT provides high spatial resolution, can discriminate between fat, muscle, bone and other soft tissues. CT out performs magnetic resonance imaging (MRI) in detecting bone erosion (Figure 3) [50], has a sensitivity of $100 \%$ and specificity of $85 \%$ [51]. MRI can provide accurate information on the size, location and extent of the tumor involvement of the soft tissues. It is not very reliable to provide information regarding bone extension, unless, there is full involvement of the medullary cavity. The MRI has a relatively higher sensitivity than CT but has lower specificity [49-52]. PET has been evaluated in primary and recurrent carcinomas of the head and 


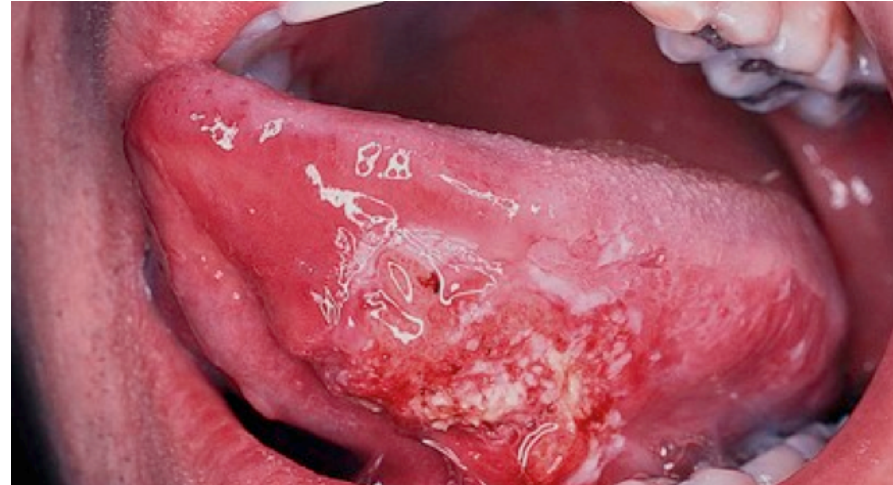

Figure 1. Ulcerated lesion of the tongue
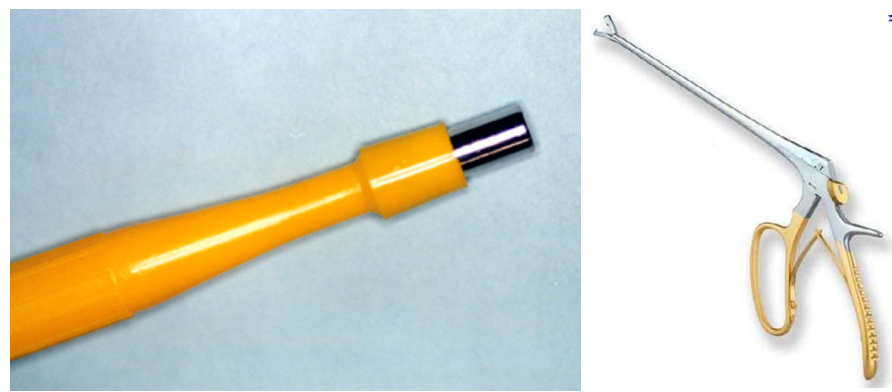

Figure 2. Punch biopsy and forceps to perform the biopsy

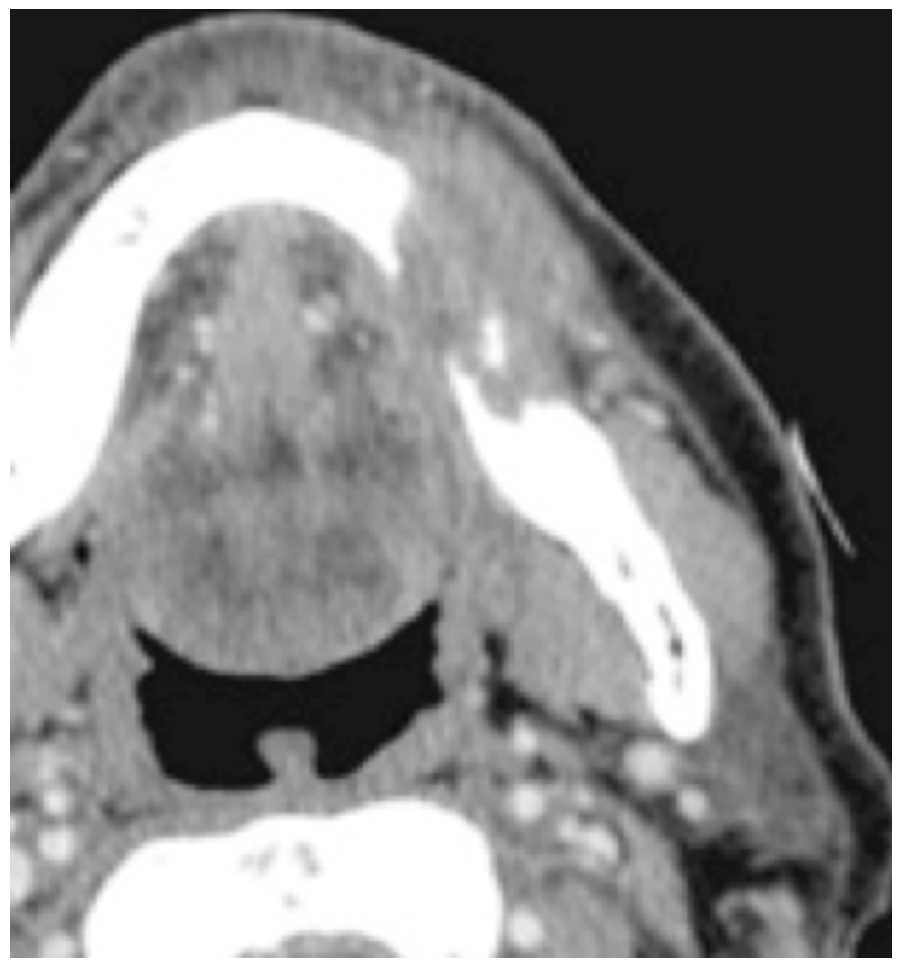

Figure 3. CT of the head and neck showing bone erosion

neck. In a multicenter, prospective study of patients newly diagnosed with a tumor of the head and neck region the results were discrepant when PET was compared with CT in $43 \%$ of cases, and the therapeutic plan was altered in $14 \%$ of patients [53]. PET should not be routinely used in the diagnosis or evaluation of patients with early tumors of the oral cavity.

\section{Pathology and histologic grade of tongue and oral cav- ity tumors}

Over $90 \%$ of head and neck cancers (including the oral cavity tumors) are SCC. The World Health Organization classifies squamous tumors of the head and neck in different histologic subtypes [54,55]:

\author{
-Conventional \\ - Verrucous \\ - Basaloid \\ - Papillary \\ - Spindle Cell (Sarcomatoid) \\ - Acantholytic \\ - Adenosquamous \\ - Cuniculatum
}

Each of these variants can develop in any of the different regions of the head and neck with the exception of the Cuniculatum subtype, that only develops in the lining of the oral cavity [56]. Variants of SCC frequently arise within the mucosa of the upper aero digestive tract, accounting for up to $15 \%$ of SCCs in these areas. The most common variants include verrucous, exophytic or papillary, spindlecell (sarcomatoid), basaloid and adenosquamous carcinoma. Each of these variants has a unique histomorphologic appearance, which raises a number of different differential diagnostic considerations, with the attendant clinically relevant management decisions. Stage for stage each one of these different subtypes of SCC has the same prognosis and are management identically.

Broder's grading system was the first of the systems, which initiated quantitative grading of cancer. This classification system was based on the estimated ratio of differentiated to undifferentiated elements in the tumor. There are four histologic grades based on the amount of keratinization [56,57]:

- Well-differentiated tumor-> 75\% keratinization.

- Moderately differentiated tumor-50-75\% keratinization.

- Poorly differentiated tumor-25-50\% keratinization.

- Anaplastic or undifferentiated tumor- $<25 \%$ keratinization.

Histologic grade is not a consistent predictor of clinical behavior. The characteristics that predict aggressive behavior include perineural infiltration, lymphatic invasion, and tumor extension beyond the capsule of the lymph nodes [56,58].

Immunohistochemical studies may be useful in poorly differentiated lesions to help make the diagnosis because SCC's express epithelial markers such as cytokeratin's. Squamous cells are immune-positive for certain cytokeratin's such as AE1/AE3 and pancytokeratin's. CK5/CK6 and p63 are also excellent markers for squamous differentiation [59].

\section{Concept of field cancerization (field defect)}

It is an important concept related to the natural history of oral cavity cancer. The term describes diffuse injury of the epithelium of the head and neck region, lung and esophagus resulting from chronic exposure to carcinogens [60]. Clinically field cancerization manifests by the frequent occurrence of abnormalities of the mucosa, such as leukoplakia and dysplasia, beyond the margins of an oral cavity cancer 
or second primary tumors in this field. The lifetime risk of a patient with oral cavity cancer to develop a new cancer is $20-40 \%$ [61].

\section{TNM classification of tumors of the head and neck}

The TNM staging system of the AJCC maintains uniformity in the staging of head and neck tumors and is based on the best estimate of the extent of disease prior to treatment (Tables 2-5). Assessment of the primary tumor is based on inspection and palpation when possible, by indirect mirror examination and direct endoscopy when necessary [62].

The prognosis is strongly correlated with the stage of the disease at diagnosis. Survival of patients with stage I disease exceeds $80 \%$ [2]. For patients with locally advanced disease at the time of diagnosis (i.e., stage III and IV), survival drops below 40\% [63]. The development of metastases in lymph nodes reduces the survival of a patient with a small primary tumor by $50 \%[2,3]$. Most patients with head and neck cancers at the time of diagnosis are found to be stage III or IV [62,64].

\section{Patterns of relapse}

Despite aggressive treatment of the primary most relapses occur within the same region of the primary oral cavity tumor. Local and

Table 1. Estimated new cases and mortality for the year 2018 in the United States [1]

\begin{tabular}{|c|c|c|}
\hline & Estimated New Cases & Estimated Deaths \\
\hline Oral Cavity and Pharynx & 51,540 (M: 37,160; F: 14,380) & 10,030 (M: 7,280; F: 2,750) \\
Tongue & 17,111 (M: 12,490; F: 4,620) & $2,510(\mathrm{M}: 1,750 ; \mathrm{F}: 760)$ \\
Floor of the Mouth & $13,580(\mathrm{M}: 7,980 ; \mathrm{F}: 5,600)$ & $2,650(\mathrm{M}: 1,770 ; \mathrm{F}: 880)$ \\
Other site of the oral cavity & 3,260 (M: 2,440; F: 820) & $1,640$ (M: 1,$280 ; \mathrm{F}: 360)$ \\
\hline
\end{tabular}

Table 2. TNM classification of oral cavity cancer - primary tumor (T) [62]

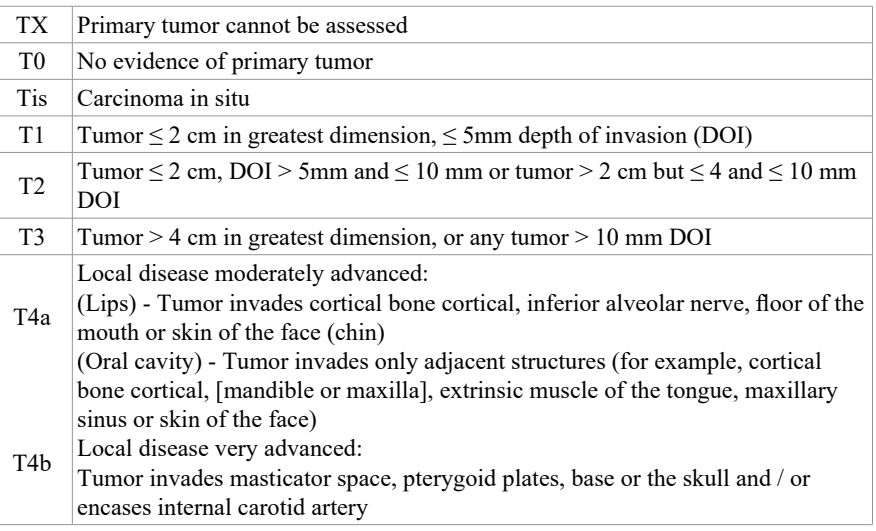

Table 3. TNM classification of oral cavity cancer - lymph nodes (N) [62]

\begin{tabular}{|l|l}
\hline NX & Region lymph nodes cannot be assessed
\end{tabular}

NO No region lymph nodes metastasis

N1 Metastasis in single ipsilateral lymph, $\leq 3 \mathrm{~cm}$ in greatest dimension ENE (-) Metastasis in single ipsilateral lymph, $>3 \mathrm{~cm}$, but $\leq 6 \mathrm{~cm}$ in greatest dimension ENE (-)

N2 Metastasis in multiple ipsilateral lymph nodes, none $>6 \mathrm{~cm}$ in greatest dimension ENE (-)

Metastasis in bilateral o contralateral lymph nodes, none $>6 \mathrm{~cm}$ $\mathrm{cm}$ in greatest dimension ENE (-)

N2a Metastasis in single ipsilateral lymph, $>3 \mathrm{~cm}$, but $\leq 6 \mathrm{~cm}$ in greatest dimension

N2b ENE (-)

N2c Metastasis in multiple ipsilateral lymph nodes, none $>6 \mathrm{~cm}$ in greatest dimension ENE (-)

Metastasis in bilateral o contralateral lymph nodes, none $>6$ $\mathrm{cm}$ in greatest dimension ENE (-)

N3 Metastasis in a lymph node $>6 \mathrm{~cm}$ in greatest dimension ENE (-) or metastasis in any node (s) and clinically overt ENE $(+)$

N3a Metastasis in a lymph node $>6 \mathrm{~cm}$ in greatest dimension ENE (-)

N3b Metastasis in any node (s) and clinically overt ENE (+)
Table 4. TNM classification of oral cavity cancer - distance metastasis (M) [62]

\begin{tabular}{|c|c|}
\hline M0 & No distant metastasis \\
\hline M1 & Distant metastasis \\
\hline
\end{tabular}

Table 5. Anatomical staging and prognostic groups [62]

\begin{tabular}{|c|c|c|c|}
\hline Staging & T & N & M \\
\hline 0 & Tis & N0 & M0 \\
\hline I & T1 & N0 & M0 \\
\hline II & T2 & N0 & M0 \\
\hline & T3 & N0 & M0 \\
\hline \multirow{2}{*}{ III } & T1 & N1 & M0 \\
& T2 & N1 & M0 \\
& T3 & N0 & M0 \\
\hline & T4a & N1 & M0 \\
& T4a & N2 & M0 \\
& T1 & N2 & M0 \\
& T2 & T3 & N1 \\
\hline IVB & T4a & Nny N & M0 \\
\hline IVC & Any T & Any N & M0 \\
\hline
\end{tabular}

regional recurrences represent approximately $80 \%$ of primary treatment failures [65]. Distant metastases increase as the disease progresses and more frequently include the lungs, and to a lesser extent, bone and liver. This is a reason to use PET/CT for assessing the distant spread of the cancer in patients with disease recurrence of progression. In 10-30\% of patients distant metastases are detected at the time of death [63].

\section{Treatment options}

Management of tongue cancers requires a multidisciplinary team made up of a surgical oncologist specialized in head and neck cancers, dentist, prosthodontist, plastic reconstructive surgeons, medical oncologist, radiation oncologist, speech therapist, fiscal rehabilitation therapist, social worker, and psychologist.

The treatment depends on the site, the extent of the primary tumor, and lymph node status, and may include $[49,63,66]$ :

- Surgery alone.

- Radiation therapy alone.

- A combination of the above.

The best therapeutic approach for the primary tumor depends on the anatomic site. Most early cancers of the tongue can be treated equally well with surgery or radiation therapy, therefore the method chosen to treat the neck is based on the mode that has been selected for the primary tumor. When the primary tumor is treated with radiation, regional lymph nodes "at risk" are incorporated into the field of treatment [3]. Patient factors and experience should influence the choice of treatment. Due to the lower morbidity of primary surgical resection of oral tongue tumors compared to primary radiation therapy most international guidelines recommend surgery as the primary modality [67]. Larger cancers may require composite resections with reconstruction of the defect by pedicle flaps and often require adjuvant therapy with radiation and chemotherapy $[68,69]$.

The classical surgical principles of oncology are applied to tongue cancers. Complete en bloc resection is necessary. Ensuring adequate margins can be challenging due to the important structures in this area [70]. The reconstruction after surgery is complex after resection 
of tumors of the tongue because the surgical procedure may have an important impact on speech and swallowing. Experienced surgeons should perform the decisions regarding the extent of resection. Prosthodontic rehabilitation is important, especially in the early stages of cancer, to ensure better quality of life.

For lesions of the oral tongue, surgery should revmove all macroscopic evidence of the disease keeping in mind the possibility of microscopic extension. If regional nodes are positive, cervical lymph node dissection is usually done in the same procedure. Neck dissection must be standardized (i.e. complete anatomical dissections, instead of random biopsies) in these situations to prevent incomplete surgery. Elective neck dissection is recommended for patients who have a oral cavity tumors with a minimum thickness of $4 \mathrm{~mm}$ [3], although some researchers believe that tumor thickness of $2-3 \mathrm{~mm}$ would be a more appropriate cut off [71,72] (Table 6).

Supraomohyoid neck dissection is recommended in patients with a clinical stage N0 who are treated surgically. There is evidence of skip metastases through the levels of the neck [73] and in some cases just involving level IV without involving the first levels. Therefore some authors recommend extended supraomohyoid neck dissection [73]. Bilateral neck dissection is performed if the tumor is close to or abutting the midline.

Sentinel lymph node (SLN) biopsy is another new option to standard elective neck dissection for identifying an occult cervical metastasis in patients with an early (T1 or $\mathrm{T} 2$ ) oral tongue cancer in centers where expertise for this procedure exists [74,75]. Patients who are found to have metastatic disease in their SLN's must undergo a completion neck dissection while those without a positive SLN can be observed with close follow up. The precision of the SLN biopsy for staging of the neck in early oral cavity cancer has been tested at length in multiple single-center trials and in two mutli-institutional studies against the reference standard of elective neck dissection with a pooled estimated sensitivity of 0.93 and negative predictive value ranging from 0.88 to 1 [74-79]. This is a technically demanding procedure that has a steep learning curve in which the success rate is dependent on the experience and expertise of the surgeon. Up to know a direct comparison with the policy of elective neck dissection is lacking [77], so we recommend using this procedure very selectively. For example, very early carcinomas of the oral cavity (T1 or may be T2), excluding floor of the mouth tumors because the accuracy in the studies we have up to date is inferior to other anatomical sites within the oral cavity such as the tongue [74,76], that have a tumor thickness less than $4 \mathrm{~mm}$.

Radiation therapy for cancer of the oral cavity may be administered as external beam radiotherapy (EBRT) or interstitial implantation alone. It is difficult getting enough dose to primary with brachytherapy while still delivering adequate dose to the regional nodes, so for many sites using both modalities produces better control and better functional outcomes [80]. Small superficial cancers can be treated very successfully by local implantation using any of the various radioactive sources (intraoral cone therapy, or electrons) [81]. Larger lesions are frequently managed using external beam radiotherapy, which includes the primary site and regional lymph nodes (even if not clinically affected) [63]. Supplementation with interstitial radiation sources

Table 6. Thickness of oral cancer predicts survival and failure [72]

\begin{tabular}{|c|c|c|}
\hline Tumor Thickness & 5 y Overall Survival & Treatment Failure \\
\hline$<2 \mathrm{~mm}$ & $97 \%$ & $2 \%$ \\
\hline $2-8 \mathrm{~mm}$ & $83 \%$ & \\
\hline$>8 \mathrm{~mm}$ & $65 \%$ & $45 \%$ \\
\hline
\end{tabular}

may be required to achieve adequate doses for bulky large primary tumors and / or lymph node metastases. A review of published clinical results of radical radiation therapy for head and neck tumors suggests a significant loss of local control when the administration of radiation therapy was prolonged, therefore, lengthening of standard treatment programs should be avoided whenever possible $[82,83]$.

Radiation therapy with curative intent usually involves daily treatment for 6 to 7 weeks (total dose: 60-70 Gy) [67]. Although there is no loss of tissue with radiation therapy as with surgery, potential complications include dry mouth, tissue fibrosis, trismus, bone necrosis, hypothyroidism, and dysphagia [84-86]. Some of these problems are common and debilitating enough to require significant attention during treatment planning. Surgery often results in less morbidity in the oral cavity, while radiation therapy causes less morbidity in other regions such as the oropharynx, larynx and nasopharynx.

The definitive indications for postoperative radiotherapy are positive margins, multiple positive nodes with metastatic disease, and extra capsular nodal extension [66,87]. Less certain indications include lymphovascular space invasion, perineural spread, single encapsulated positive lymph node, and thick tumors [87]. Tumors with a thickness between 3 to $9 \mathrm{~mm}$ have $44 \%$ subclinical node positivity and a $7 \%$ local recurrence rate and tumors with a thickness greater than 9 mm thickness have $53 \%$ subclinical node positivity and a $24 \%$ local recurrence rate [87].

Postoperative radiotherapy (60 to $70 \mathrm{~Gy}$ in 6-7 weeks) reduces the rate of local and regional recurrence from $50-15 \%$ for tumors with pathologic features that predict a high local and regional failure rates $[81,88,89]$. The indications for postoperative radiotherapy are well established and are outlined in Table 7.

Two randomized clinical trials were conducted to determine whether adding chemotherapy to radiation therapy improves local / regional control and survival in high-risk patients with head and neck cancers after definitive surgical resection. The results of these trials were published in 2004 [88,90] (Table 8).

In a comparative analysis of the two trials, the presence of extracapsular extension and / or microscopically involved surgical margins were the only risk factors for the positive impact that chemo radiation had over improved survival [91]. The adjuvant treatment for patients with oral tongue cancers is summarized in Table 9.

Recently the results of the RTOG-0234 examining concurrent chemoradiotherapy and cetuximab in the postoperative treatment of patients with head and neck squamous cell carcinoma (HNSCC) with high-risk pathologic features was published [92]. The study recruited 238 patients were with stage III to IV HNSCC with gross total resection showing positive margins and/or extracapsular nodal extension and/ or two or more nodal metastases. Patients were randomly assigned to $60 \mathrm{~Gy}$ radiation with cetuximab once per week plus either cisplatin 30 $\mathrm{mg} / \mathrm{m} 2$ or docetaxel $15 \mathrm{mg} / \mathrm{m} 2$ once per week. With a median followup of 4.4 years, 2 -year overall survival (OS) was $69 \%$ for the cisplatin arm and 79\% for the docetaxel arm; 2-year disease-free survival (DFS) was $57 \%$ and $66 \%$, respectively. DFS in this study was compared with that in the chemoradiotherapy arm of the RTOG-9501 trial, which had a hazard ratio of 0.76 for the cisplatin arm versus control $(\mathrm{P}=0.05)$ and 0.69 for the docetaxel arm versus control $(\mathrm{P}=0.01)$, reflecting absolute improvement in 2 -year DFS of $2.5 \%$ and $11.1 \%$, respectively. The delivery of postoperative chemoradiotherapy and cetuximab to patients with HNSCC is possible and tolerated with predictable toxicity. The docetaxel regimen shows favorable outcome with improved DFS and 
Table 7. Possible Indications for postoperative radiotherapy

Close or positive margins

An affected lymph node $>3 \mathrm{~cm}$

Multiple lymph nodes involved

Extra capsular extension (ECE)

Patients who had an open biopsy of a suspicious neck node and did not undergo neck dissection at the time

Perineural invasion, lymphovascular space invasion, invasion of cartilage, bone or deep soft tissues

Recommendation of the surgeon due to intraoperative findings

Table 8. Results from the EORTC 22931 and RTOG 9501 Studies

\begin{tabular}{|l|c|c|c|c|c|c|}
\hline \multicolumn{3}{|c|}{} & \multicolumn{3}{|c|}{ EORTC 22931 } & \multicolumn{3}{c|}{ RTOG 9501 } \\
\hline End Point & RT & RT + CT & P Value & RT & RT + CT & P Value \\
\hline 5 y Disease Free Survival & $36 \%$ & $47 \%$ & 0.04 & $61 \%$ & $78 \%$ & 0.004 \\
\hline LR Control & $69 \%$ & $82 \%$ & 0.007 & $72 \%$ & $82 \%$ & 0.01 \\
\hline OS & $40 \%$ & $53 \%$ & 0.002 & $57 \%$ & $63 \%$ & 0.19 \\
\hline
\end{tabular}

Table 9. Summary of adjuvant treatment of oral cavity cancers

\begin{tabular}{|l|l|}
\hline $\begin{array}{l}\text { Risk Based on Factors for Treatment } \\
\text { Failure }\end{array}$ & Management \\
\hline Low Risk & No adjuvant radiation \\
\hline Intermediate Risk (- Margin, - ECE) & Radiation therapy (60 Gy) \\
\hline High Risk (+ Margin and/or + ECE) & Chemo radiation (60-66 Gy) with Cisplatin \\
\hline
\end{tabular}

OS relative to historical controls and has commenced formal testing in a phase II/III trial (RTOG 1216).

The recommendations for follow-up are based on the risk of relapse, second primaries, treatment sequelae, and toxicities includes a history and physical (including a complete head and neck exam; mirror and fiberoptic examinations as clinically indicated every 1 to 3 months for the first year, every 2-6 months for the second year, every 4 to 8 months years 3 to 5 , and every 12 months after 5 years. To facilitate this our group sees the patient every three months for the first five years. Post-treatment baseline imaging of the primary (and neck, if treated) is recommended within 6 months of treatment, further imaging is indicated based on signs and symptoms (but is not routinely recommended without worrisome manifestations). Chest imaging as clinically indicated for patients with a smoking history. If the neck was radiated, the NCCN guidelines recommend thyroid stimulating hormone (TSH) testing every 6 to 12 months. Smoking and alcohol counseling as clinically indicated [67].

\section{Conclusion}

Cancer of the oral tongue requires a multidisciplinary team approach to their management that includes a surgical oncologist, medical oncologist, radiation oncologist, dentist, oral maxillary surgeon, prosthodontist, rehabilitation therapists, rehabilitation speech therapist, as well as of emotional support by psychologists or social workers. Early referral to a center that has the expertise in the management of these complex tumors has been shown to improve outcomes and is highly encouraged.

\section{References}

1. Society AC (2018) Cancer Facts and Figures 2018. Atlanta: American Cancer Society.

2. Siegel R, Ma J, Zou Z, Jemal A (2014) Cancer statistics, 2014. Cancer J Clin 64: 9-29. [Crossref]

3. Ridge JA (2013) Cancer Management: A Multidisciplinary Approach Medical, Surgical, and Radiation Oncology. Head and Neck Tumors, ed. L.D.W. Damiel G. Haller, Kevin A, CAmphausen, William J, Hoskins. Cancer Network Home of the Journal Oncology: Cancer Network.
4. Day GL, Blot WJ (1992) Second primary tumors in patients with oral cancer. Cancer 70: 14-19.

5. Lindberg R (1972) Distribution of cervical lymph node metastases from squamous cell carcinoma of the upper respiratory and digestive tracts. Cancer 29: 1446-1449. [Crossref]

6. Smith D (1991) Taste and smell dysfunction. In: Paparella MM, Gluckman JL, Meyerhoff W ( $3^{\text {rd }}$ ed.) Otolaryngology. Philadelphia: WB Saunders Co.

7. Oliver H. Beahrs, MMEJ (2004) Neck. Surgical Anatomy, The Embryologic and Anatomic Basis of Modern Surgery. Skandalakis J (ed.), Athens, Greece: Paschalidis Medical Publications.

8. TS (2004) Head and neck. Medical Embryology. Langman's SB. Philadelphia Lippincott Williams \& Wilkins.

9. HG (2000) Anatomy of the Human Body. Philadelphia: Lea \& Febiger, Bartleby.com.

10. Roberts IM, Solomon SE, Brusco OA, Goldberg W, Bernstein JJ (1991) Neuromodulators of the lingual von Ebner gland: an immunocytochemical study. Histochemistry 96: 153-156.

11. Shah JP, Patel S, Singh B (2012) Jatin Shah's Head and Neck Surgery and Oncology 4th Edition ed., Philadelphia: Elsevier.

12. Ho PS, Ko YC, Connie Yang YH, Shieh TY, Tsai CC (2002) The incidence of oropharyngeal cancer in Taiwan: an endemic betel quid chewing area. J Oral Pathol Med 31: 213-219.

13. Goldenberg D, Lee J, Koch WM, Kim MM, Trink B, et al. (2004) Habitual risk factors for head and neck cancer. Otolaryngol Head Neck Surg 131: 986-993. [Crossref]

14. Boffetta P, Hecht S, Gray N, Gupta P, Straif K (2008) Smokeless tobacco and cancer. Lancet Oncol 9: 667-675. [Crossref]

15. Secretan B, Straif K, Baan R, Grosse Y, El Ghissassi F, et al. (2009) A review of human carcinogens--Part E: tobacco, areca nut, alcohol, coal smoke, and salted fish. Lancet Oncol 10: 1033-1034. [Crossref]

16. Gandini S, Botteri E, Iodice S, Boniol M, Lowenfels AB, et al. (2008) Tobacco smoking and cancer: a meta-analysis. Int J Cancer 122: 155-164. [Crossref]

17. Program NT (2005) Report on Carcinogens, Eleventh Edition, P.H.S. US Department of Health and Human Services, National Toxicology Program.

18. Shapiro JA, Jacobs EJ, Thun MJ (2000) Cigar smoking in men and risk of death from tobacco-related cancers. $J$ Natl Cancer Inst 92: 333-337.

19. Znaor A, Brennan P, Gajalakshmi V, Mathew A, Shanta V, et al. (2003) Independent and combined effects of tobacco smoking, chewing and alcohol drinking on the risk of oral, pharyngeal and esophageal cancers in Indian men. Int J Cancer 105: 681-686. [Crossref]

20. Hashibe M, Boffetta P, Zaridze D, Shangina O, Szeszenia-Dabrowska N, et al. (2006) Evidence for an important role of alcohol- and aldehyde-metabolizing genes in cancers of the upper aerodigestive tract. Cancer Epidemiol Biomarkers Prev 15: 696-703. [Crossref]

21. Hashibe M, Brennan P, Benhamou S, Castellsague X, Chen C, et al. (2007) Alcohol drinking in never users of tobacco, cigarette smoking in never drinkers, and the risk of head and neck cancer: pooled analysis in the International Head and Neck Cancer Epidemiology Consortium. J Natl Cancer Inst 99: 777-789. [Crossref]

22. Hashibe M, Brennan P, Chuang SC, Boccia S, et al. (2009) Interaction between tobacco and alcohol use and the risk of head and neck cancer: pooled analysis in the International Head and Neck Cancer Epidemiology Consortium. Cancer Epidemiol Biomarkers Prev 18: 541-550. [Crossref]

23. Graham S, Dayal H, Rohrer T, Swanson M, Sultz H, et al. (1977) Dentition, diet tobacco, and alcohol in the epidemiology of oral cancer. J Natl Cancer Inst 59: 16111618. [Crossref]

24. Guha N, Boffetta P, Wünsch Filho V, Eluf Neto J, Shangina O, et al. (2007) Oral health and risk of squamous cell carcinoma of the head and neck and esophagus: results of two multicentric case-control studies. Am J Epidemiol 166: 1159-1173. [Crossref]

25. Wynder EL, Kabat G, Rosenberg S, Levenstein M (1983) Oral cancer and mouthwash use. J Natl Cancer Inst 70: 255-260. [Crossref]

26. Barnes L (2005) Pathology and Genetics. W.H. Organization, IARC Press, Lyon.

27. Contreras Vidaurre EG, Bagán Sebastián JV, Gavalda C, Torres Cifuentes EF (2001) Retinoids: application in premalignant lesions and oral cancer. Med Oral 6: 114-123. [Crossref] 
28. Goldenberg D, Golz A, Joachims HZ (2003) The beverage maté: a risk factor for cancer of the head and neck. Head Neck 25: 595-601. [Crossref]

29. Hong WK, Endicott J, Itri LM, Doos W, Batsakis JG, et al. (1986) 13-cis-retinoic acid in the treatment of oral leukoplakia. N Engl J Med 315: 1501-1505. [Crossref]

30. Lippman SM, Benner SE, Hong WK (1994) Cancer chemoprevention. J Clin Oncol 12: 851-873. [Crossref]

31. Smith MA, Parkinson DR, Cheson BD, Friedman MA (1992) Retinoids in cancer therapy. J Clin Oncol 10: 839-864. [Crossref]

32. Benner SE, Winn RJ, Lippman SM, Poland J, Hansen KS, et al. (1993) Regression of oral leukoplakia with alpha-tocopherol: a community clinical oncology program chemoprevention study. J Natl Cancer Inst 85: 44-47.

33. Gasparini G, Longobardi G, Boniello R, Di Petrillo A, Pelo S (2006) Fanconi anemia manifesting as a squamous cell carcinoma of the hard palate: a case report. Head Face Med 2: 1. [Crossref]

34. Lustig JP, Lugassy G, Neder A, Sigler E (1995) Head and neck carcinoma in Fanconi's anaemia--report of a case and review of the literature. Eur J Cancer B Oral Oncol 31B: 68-72.

35. Greer RO, Goldman HM (1974) Oral papillomas. Clinicopathologic evaluation and retrospective examination for dyskeratosis in 110 lesions. Oral Surg Oral Med Oral Pathol 38: 435-440.

36. Alter BP, Giri N, Savage SA, Rosenberg PS (2009) Cancer in dyskeratosis congenita. Blood 113: 6549-6557. [Crossref]

37. Tanaka T, Tanaka M, Tanaka T (2011) Oral carcinogenesis and oral cancer chemoprevention: a review. Patholog Res Int 2011: 431246. [Crossref]

38. Sasahira T, Kirita T, Kuniyasu H (2014) Update of molecular pathobiology in oral cancer: a review. Int J Clin Oncol 19: 431-436. [Crossref]

39. Arantes LM, de Carvalho AC, Melendez ME, Carvalho AL, Goloni-Bertollo EM (2014) Methylation as a biomarker for head and neck cancer. Oral Oncol 50: 587-592. [Crossref]

40. Olasz J, Juhász A, Remenár E, Engi H, Bak M, et al. (2007) RAR beta2 suppression in head and neck squamous cell carcinoma correlates with site, histology and age. Oncol Rep 18: 105-112. [Crossref]

41. Tornesello ML, Perri F, Buonaguro L, Ionna F, Buonaguro FM, et al. (2014) HPVrelated oropharyngeal cancers: From pathogenesis to new therapeutic approaches. Cancer Lett 351: 198-205. [Crossref]

42. García Martínez J, García-Inclán C, Suárez C, Llorente JL, Hermsen MA, et al. (2014) DNA aneuploidy-specific therapy for head and neck squamous cell carcinoma. Head Neck 37: 884-888. [Crossref]

43. Erkal HS, Mendenhall WM, Amdur RJ, Villaret DB, Stringer SP (2001) Synchronous and metachronous squamous cell carcinomas of the head and neck mucosal sites. JClin Oncol 19: 1358-1362. [Crossref]

44. de Braud F, al-Sarraf M (1993) Diagnosis and management of squamous cell carcinoma of unknown primary tumor site of the neck. Semin Oncol 20: 273-278. [Crossref]

45. Layfield LJ (1996) Fine-needle aspiration of the head and neck. Pathology (Phila) 4: 409-438. [Crossref]

46. Shaha A, Webber C, Marti J (1986) Fine-needle aspiration in the diagnosis of cervical lymphadenopathy. Am J Surg 152: 420-423. [Crossref]

47. Tatomirovic Z, Skuletic V, Bokun R, Trimcev J, Radic O, et al. (2009) Fine needle aspiration cytology in the diagnosis of head and neck masses: accuracy and diagnostic problems. J BUON 14: 653-659. [Crossref]

48. Martin H (1961) Untimely lymph node biopsy. Am J Surg 102: 17-18. [Crossref]

49. Brown AE, Langdon JD (1995) Management of oral cancer. Ann R Coll Surg Engl 77: 404-408. [Crossref]

50. Mukherji SK, Isaacs DL, Creager A, Shockley W, Weissler M, et al. (2001) CT detection of mandibular invasion by squamous cell carcinoma of the oral cavity. AJR Am J Roentgenol 177: 237-243. [Crossref]

51. Steinkamp HJ, Mäurer J, Heim T, Knöbber D, Felix R (1993) Magnetic resonance tomography and computerized tomography in tumor staging of mouth and oropharyngeal cancer. HNO 41: 519-525. [Crossref]

52. Hao SP, Ng SH (2000) Magnetic resonance imaging versus clinical palpation in evaluating cervical metastasis from head and neck cancer. Otolaryngol Head Neck Surg 123: 324-327.
53. Lonneux M, Hamoir M, Reychler H, Maingon P, Duvillard C, et al. (2010) Positron emission tomography with $[18 \mathrm{~F}]$ fluorodeoxyglucose improves staging and patient management in patients with head and neck squamous cell carcinoma: a multicenter prospective study. J Clin Oncol 28: 1190-1195. [Crossref]

54. Slootweg PJ, Eveson JW (2014) Tumours of the Oral Cavity and Oropharynx, I.A.f.R.o. Cancer, Editor, pp: 163-208.

55. Thompson LDR (2003) Squamous Cell Carcinoma Variants of the Head and Neck Current Diagnostic Pathology 9: 384-396.

56. Massano J, Regateiro FS, Januário G, Ferreira A (2006) Oral squamous cell carcinoma: review of prognostic and predictive factors. Oral Surg Oral Med Oral Pathol Oral Radiol Endod 102: 67-76. [Crossref]

57. Bansberg SF, Olsen KD, Gaffey TA (1989) High-grade carcinoma of the oral cavity. Otolaryngol Head Neck Surg 100: 41-48. [Crossref]

58. Close LG, Brown PM, Vuitch MF, Reisch J, Schaefer SD (1989) Microvascular invasion and survival in cancer of the oral cavity and oropharynx. Arch Otolaryngol Head Neck Surg 115: 1304-1309. [Crossref]

59. Dabbs DJ (2006) Diagnostic Immunohistochemestry: Theranostic and Genomic Applications. Fourth Edition ed. 2006, 1600 John F. Kennedy Blvd. Philadelphia: Elsevier.

60. Slaughte DP, Southwick HW, Smejkal W (1953) Field cancerization in oral stratified squamous epithelium; clinical implications of multicentric origin. Cancer 6: 963-968.

61. Speight PM (2007) Update on oral epithelial dysplasia and progression to cancer. Head Neck Pathol 1: 61-66.

62. Edge S, Byrd DR, Comptom CC, et al. (2008) AJCC Cancer Staging Manual. 8th. ed Lip and oral cavity cancer. New York, NY: Springer, pp: 79-94.

63. Harrison LB, RB Sessions, Hong WK (2009) Head and Neck Cancer: A Multidisciplinary Approach. 3rd ed. ed. 2009, Philadelphia, PA.: Lippincott, William and Wilkins.

64. Wallner PE, Hanks GE, Kramer S, McLean CJ (1986) Patterns of Care Study. Analysi of outcome survey data-anterior two-thirds of tongue and floor of mouth. Am J Clin Oncol 9: 50-57. [Crossref]

65. Wong LY, Wei WI, Lam LK, Yuen AP (2003) Salvage of recurrent head and neck squamous cell carcinoma after primary curative surgery. Head Neck 25: 953-959. [Crossref]

66. Wang C (1997) Radiation Therapy for Head and Neck Cancers. New York: Wiley-Liss

67. Gamaletsou MN, Rammaert B, Bueno MA, Moriyama B, Sipsas NV, et al. (2014) Aspergillus osteomyelitis: epidemiology, clinical manifestations, management, and outcome. J Infect 68: 478-493. [Crossref]

68. Kramer S, Gelber RD, Snow JB, Marcial VA, Lowry LD, et al. (1987) Combined radiation therapy and surgery in the management of advanced head and neck cancer: final report of study 73-03 of the Radiation Therapy Oncology Group. Head Neck Surg 10: 19-30. [Crossref]

69. Peters LJ, Goepfert H, Ang KK, Byers RM, Maor MH, et al. (1993) Evaluation of the dose for postoperative radiation therapy of head and neck cancer: first report of a prospective randomized trial. Int J Radiat Oncol Biol Phys 26: 3-11. [Crossref]

70. Looser KG, Shah JP, Strong EW (1978) The significance of "positive" margins in surgically resected epidermoid carcinomas. Head Neck Surg 1: 107-111.

71. McGuirt WF Jr, Johnson JT, Myers EN, Rothfield R, Wagner R (1995) Floor of mouth carcinoma. The management of the clinically negative neck. Arch Otolaryngol Head Neck Surg 121: 278-282.

72. Spiro RH, Huvos AG, Wong GY, Spiro JD, Gnecco CA, et al. (1986) Predictive value of tumor thickness in squamous carcinoma confined to the tongue and floor of the mouth. Am J Surg 152: 345-350.

73. Byers RM, Weber RS, Andrews T, McGill D, Kare R, et al. (1997) Frequency and therapeutic implications of "skip metastases" in the neck from squamous carcinoma of the oral tongue. Head Neck 19: 14-19. [Crossref]

74. Civantos FJ, Zitsch RP, Schuller DE, Agrawal A, Smith RB, et al. (2010) Sentine lymph node biopsy accurately stages the regional lymph nodes for T1-T2 oral squamous cell carcinomas: results of a prospective multi-institutional trial. $J$ Clin Oncol 28: 1395-1400.

75. Govers TM, Hannink G, Merkx MA, Takes RP, Rovers MM (2013) Sentinel node biopsy for squamous cell carcinoma of the oral cavity and oropharynx: a diagnostic meta-analysis. Oral Oncol 49: 726-732. [Crossref] 
76. Alkureishi LW, Ross GL, Shoaib T, Soutar DS, Robertson AG, et al. (2010) Sentinel node biopsy in head and neck squamous cell cancer: 5-year follow-up of a European multicenter trial. Ann Surg Oncol 17: 2459-2464. [Crossref]

77. Samant S (2014) Sentinel node biopsy as an alternative to elective neck dissection for staging of early oral carcinoma. Head Neck 36: 241-246. [Crossref]

78. Pezier T, Nixon IJ, Gurney B, Schilling C, Hussain K, et al. (2012) Sentinel lymph node biopsy for T1/T2 oral cavity squamous cell carcinoma--a prospective case series. Ann Surg Oncol 19: 3528-3533. [Crossref]

79. Broglie MA, Haerle SK, Huber GF, Haile SR, Stoeckli SJ (2013) Occult metastases detected by sentinel node biopsy in patients with early oral and oropharyngeal squamous cell carcinomas: impact on survival. Head Neck 35: 660-666.

80. Wendt CD, Peters LJ, Delclos L, Ang KK, Morrison WH, et al. (1990) Primary radiotherapy in the treatment of stage I and II oral tongue cancers: importance of the proportion of therapy delivered with interstitial therapy. Int J Radiat Oncol Biol Phys 18: $1287-1292$.

81. de Visscher JG, Botke G, Schakenraad JA, van der Waal I (1999) A comparison of results after radiotherapy and surgery for stage I squamous cell carcinoma of the lower lip. Head Neck 21: 526-530. [Crossref]

82. Fowler JF, Lindstrom MJ (1992) Loss of local control with prolongation in radiotherapy. Int J Radiat Oncol Biol Phys 23: 457-467. [Crossref]

83. Langendijk JA, de Jong MA, R Leemans Ch, de Bree R, Smeele LE, et al. (2003) Postoperative radiotherapy in squamous cell carcinoma of the oral cavity: the importance of the overall treatment time. Int J Radiat Oncol Biol Phys 57: 693-700.

84. Trotti A, Bellm LA, Epstein JB, Frame D, Fuchs HJ, et al. (2003) Mucositis incidence, severity and associated outcomes in patients with head and neck cancer receiving radiotherapy with or without chemotherapy: a systematic literature review. Radiother Oncol 66: 253-262. [Crossref]
85. Dirix P, Nuyts S, Vander Poorten V, Delaere P, Van den Bogaert W (2008) The influence of xerostomia after radiotherapy on quality of life: results of a questionnaire in head and neck cancer. Support Care Cancer 16: 171-179. [Crossref]

86. Cooper JS, Fu K, Marks J, Silverman S (1995) Late effects of radiation therapy in the head and neck region. Int J Radiat Oncol Biol Phys 31: 1141-1164. [Crossref]

87. Po Wing Yuen A, Lam KY, Lam LK, Ho CM, Wong A, et al. (2002) Prognostic factors of clinically stage I and II oral tongue carcinoma-A comparative study of stage, thickness, shape, growth pattern, invasive front malignancy grading, Martinez-Gimeno score, and pathologic features. Head Neck 24: 513-520. [Crossref]

88. Cooper JS, Pajak TF, Forastiere AA, Jacobs J, Campbell BH, et al. (2004) Postoperative concurrent radiotherapy and chemotherapy for high-risk squamous-cell carcinoma of the head and neck. N Engl J Med 350: 1937-1944. [Crossref]

89. Yorozu A, Sykes AJ, Slevin NJ (2001) Carcinoma of the hard palate treated with radiotherapy: a retrospective review of 31 cases. Oral Oncol 37: 493-497.

90. Bernier J, Domenge C, Ozsahin M, Matuszewska K, Lefèbvre JL, et al. (2004) Postoperative irradiation with or without concomitant chemotherapy for locally advanced head and neck cancer. $N$ Engl J Med 350: 1945-1952. [Crossref]

91. Bernier J, Cooper JS, Pajak TF, van Glabbeke M, Bourhis J, et al. (2005) Defining risk levels in locally advanced head and neck cancers: a comparative analysis of concurrent postoperative radiation plus chemotherapy trials of the EORTC (\#22931) and RTOG (\# 9501). Head Neck 27: 843-850. [Crossref]

92. Harari PM, Harris J, Kies MS, Myers JN, Jordan RC, et al. (2014) Postoperative Chemoradiotherapy and Cetuximab for High-Risk Squamous Cell Carcinoma of the Head and Neck: Radiation Therapy Oncology Group RTOG-0234. J Clin Oncol 32: 2486-2495.

Copyright: (C2018 Arrangoiz R. This is an open-access article distributed under the terms of the Creative Commons Attribution License, which permits unrestricted use, distribution, and reproduction in any medium, provided the original author and source are credited. 